\title{
Survey of Workers' Opinions Regarding Health Consultations by Occupational Physicians
}

\author{
Yasushi KUdo ${ }^{1}$; Toshihiko SATOH ${ }^{1}$; Eriko MiYaJima ${ }^{1}$; Kaori Hosor ${ }^{1}$; Mitsuyasu Watanabe ${ }^{1}$; Takeo Miki ${ }^{1}$; \\ and Yoshiharu AIzawA ${ }^{1}$
}

${ }^{I}$ Department of Preventive Medicine and Public Health, Kitasato University School of Medicine

\begin{abstract}
The aim of this study was to discover ways to improve the functionality of health consultations by occupational physicians. A self-administered questionnaire survey was conducted for 497 workers of a manufacturing plant. A standard partial regression coefficient was computed by multiple linear regression analysis, with the workers' perceived helpfulness of health consultations by occupational physicians as the dependent variable, and the basic attributes of subjects, occupational physicians' dedication, overtime hours, fatigue accumulation, and privacy protection as independent variables. Workers who felt that occupational physicians were dedicated and privacy protection was observed tended to feel that health consultations by occupational physicians were helpful. Blue-collar workers and workers without a family physician also felt that health consultations by occupational physicians were helpful. For health consultations by occupational physicians to work effectively, it is necessary to help workers realize the occupational physicians' dedication and to convey to the workers the absolute assurance of their privacy protection. It is also necessary to convey the importance of providing health consultations by occupational physicians for blue-collar workers and workers without a family physician.
\end{abstract}

Key Words Long Working Hours, Occupational Physicians, Industrial Safety and Health Law, Health Consultation, Occupational Field

\section{INTRODUCTION}

Long working hours cause health impairment, such as hypertension and cardiac infarction. ${ }^{[1]-[3]}$ Health consultations by occupational physicians are useful for preventing workers from suffering such prolonged work-related health impairment.

In Japan, the Industrial Safety and Health Law was amended, and the amended version has been in effect since April 2006. ${ }^{[4]}$ The amended law stipulates, "If an employee monthly overtime exceeds 100 hours, and fatigue accumulation is noticed, the employer must arrange a health consultation by a physician for the employee upon the employee's request." This provision mentions, "upon an employee's request," a health consultation will be conducted.

In addition, some employers may encourage workers who

Received: November 21, 2006

${ }^{1}$ Address; Department of Preventive Medicine and Public Health, Kitasato University School of Medicine 1-15-1, Kitasato, Sagamihara, Kanagawa, 228-8555 Japan. TEL: 81-42-778-9352, FAX: 81-42-778-9257, E-mail: work considerable overtime to receive health consultations by occupational physicians. However, when employees are not aware of the necessity of receiving such health consultations, they will naturally not voluntarily request one. And as a result, sufficient effects of health consultations by occupational physicians cannot be expected.

In the wake of the amendment of the Industrial Safety and Health Law, it is expected that the importance of health consultations by occupational physicians will become greater than before. However, there have been no reports on the workers' perceived helpfulness of health consultations by occupational physicians. The aimed study was to clarify measures for improving the functionality of health consultations by occupational physicians.

\section{METHODS}

\section{Subjects and distribution/recovery of a questionnaire}

There were a total of 497 workers in a manufacturing plant who were the subjects for this survey who worked in departments manufacturing industrial products and design development. The plant mainly recruits high school graduates as blue-collar workers and university graduates or postgraduates as white-collar workers.

About 2 weeks before the first day of a regular periodic health checkup, each subject received an anonymous selfadministered questionnaire (Appendix 1), an envelope for the return of the questionnaire, and the description of this study. The description included: 1) the purpose and methods of the study, 2) clarification of the concept of voluntary cooperation in this study, 3) the fact that submitting the questionnaire indicates the respondent's consent to cooperate, 4) a statement of privacy protection, 5) the fact that the information collected in this study will be disclosed to examinees unless there is a risk that such disclosure would intrude on someone's privacy, 6) the fact that the outcome of this study will be published in academic journals and/or presented at academic conferences, 7) the method for managing the data, 8) the fact that examinees will not incur any charges, 9) the names and positions of researchers, and 10) contact information. The completed questionnaire was then placed into the envelope provided, and the envelope was sealed before taking the health checkup. Subsequently, the envelopes were collected from a collection box at the site of the periodic health checkup. 
Table 1 Distribution of analyzed subjects.

\begin{tabular}{crc}
\hline Age & $N$ & $\%$ \\
\hline-29 & 63 & 17.1 \\
$30-39$ & 118 & 32.0 \\
$40-49$ & 133 & 36.0 \\
$50-59$ & 55 & 14.9 \\
\hline Total & 369 & 100 \\
\hline
\end{tabular}

There have been no previous studies on workers' perceived helpfulness of health consultations by occupational physicians. Therefore, we consulted with occupational health staff and produced original questions for the questionnaire (Appendix) while referring to the amended Industrial Safety and Health Law, ${ }^{[4]}$ literature that focused on occupational health activities, ${ }^{[5]}$ and literature on surveys of patient satisfaction. ${ }^{[6]-[9]}$ The questionnaire was divided into two categories: subjects' basic attributes (Question set 1) and everyday thoughts (Question set 2).

The questionnaires of 402 respondents among 497 subjects were collected $(80.9 \%)$. Among them, questionnaires that had missing values were excluded from the analyses. Because the number of female workers was very small (12), they were excluded from the study. Consequently, a total of 369 questionnaires were analyzed. The average age was 39.3 years (range: 19-59 years) (Table 1).

\section{Statistical analyses}

The Kruskal-Wallis test was performed in order to examine the workers' perceived helpfulness of health consultations by occupational physicians in relation to age (10-year intervals), health condition, occupational physicians' dedication, overtime hours, fatigue accumulation, and privacy protection. The Mann-Whitney U test was performed in order to examine the workers' perceived helpfulness of health consultations by occupational physicians in relation to marital status, abnormal findings, family physician, and occupation. The standard partial regression coefficient was computed by multiple linear regression analysis, with workers' perceived helpfulness of health consultations by occupational physicians as the dependent variable, and basic attributes of the subjects, occupational physicians' dedication, overtime hours, fatigue accumulation, and privacy protection as independent variables. In the multiple regression analysis, marital status, abnormal findings, family physician, and occupation were used as dichotomous variables. The subjects' actual ages were used. Concerning the health condition, 1-5 points were given from "poor" to "good." Concerning occupational physicians' dedication, overtime hours, fatigue accumulation, and privacy protection, 1-5 points were given from "definitely disagree" to "definitely agree." Concerning health consultations by occupational physicians, 1-5 points were given from "definitely disagree" to "definitely agree." SPSS $11.5 \mathrm{~J}$ for Windows was used for all analyses.

\section{RESULTS}

The association between the workers' perceived helpfulness of health consultations by occupational physicians and the basic attributes of the subjects is shown in Table 2. The Kruskal-Wallis test showed that there were significant differences in the health conditions among the employees $(P=0.037)$.

The association of the workers' perceived helpfulness of health consultations by occupational physicians and other factors, the physicians' dedication, overtime, fatigue accumulation, and privacy protection, is shown in Table 3 . The Kruskal-Wallis test showed that there were significant differences among the employees' perceptions of occupational physicians' dedication $(P<0.001)$ and privacy protection $(P<0.001)$.

The results of multiple regression analysis are shown in Table 4. Because the VIF (variance inflation factor) values were from 1.084 to 1.518 , multicollinearity does not occur. ${ }^{[10]}$ The workers' perceived helpfulness of health consultations by occupational physicians significantly correlated with the occupational physicians' dedication $(P<0.001)$, privacy protection $(P<0.001)$, family physician $(P=0.015)$, and occupation $(P=0.004)$.

\section{DISCUSSION}

This particular plant has about 5,500 employees, 2 fulltime occupational physicians (a man and a woman), and an on-site clinic. In addition, this plant has conducted health consultations by the occupational physicians for workers whose overtime exceed 100 hours a month since before the amendment of the Industrial Safety and Health Law. ${ }^{[4]}$ The workers' average overtime is about 45 hours, and there is an average of 5 staff working 100 hours or more per month.

It is difficult to distribute and collect questionnaires during regular daily working hours due to the interruption of work it would cause. The questionnaire survey on the day of the periodic health checkup was considered, however, considerable confusion was anticipated on that day. Therefore, the occupational health staff asked the manager of each department to cooperate in this research. Questionnaires were then distributed to the cooperative departments and subsequently collected using a collection box at the site of the periodic health checkup.

Hayashi et al. ${ }^{[1]}$ compared the blood pressure of workers whose overtime was an average of 60 hours or more per month and for those whose overtime was on average 30 hours or less per month among a group of employees with normal blood pressure. Comparisons were made among a group of workers with mild hypertension. As a result, in both the groups of normal blood pressure and mild hypertension, the blood pressure of the employees whose overtime exceeded an averaged of 60 hours per month was significantly higher than that of workers whose overtime averaged less than 30 hours per month.

Iwasaki $^{[2]}$ categorized subjects into a long-working-hour group and a short-working-hour group, and measured the blood pressure of each employee. As a result, for workers in their $50 \mathrm{~s}$ and $60 \mathrm{~s}$, the systolic blood pressure of the long- 
Table 2 The association between workers' perceived helpfulness of health consultations by occupational physicians and basic attributes of subjects.

\begin{tabular}{|c|c|c|c|c|c|c|c|}
\hline & $\begin{array}{c}\text { Definitely } \\
\text { agree }\end{array}$ & $\begin{array}{c}\text { Somewhat } \\
\text { agree }\end{array}$ & $\begin{array}{c}\text { Neither agree } \\
\text { nor disagree }\end{array}$ & $\begin{array}{c}\text { Somewhat } \\
\text { disagree }\end{array}$ & $\begin{array}{c}\text { Definitely } \\
\text { disagree }\end{array}$ & Total & $P$ value \\
\hline \multicolumn{8}{|l|}{ Age } \\
\hline-29 & $3(4.8 \%)$ & $19(30.2 \%)$ & $31(49.2 \%)$ & $7(11.1 \%)$ & $3(4.8 \%)$ & $63(100 \%)$ & \multirow{4}{*}{0.150} \\
\hline $30-39$ & $10(8.5 \%)$ & $33(28.0 \%)$ & $51(43.2 \%)$ & $18(15.3 \%)$ & $6(5.1 \%)$ & $118(100 \%)$ & \\
\hline $40-49$ & $11(8.3 \%)$ & $50(37.6 \%)$ & $56(42.1 \%)$ & $8(6.0 \%)$ & $8(6.0 \%)$ & $133(100 \%)$ & \\
\hline $50-59$ & $7(12.7 \%)$ & $20(36.4 \%)$ & $21(38.2 \%)$ & $5(9.1 \%)$ & $2(3.6 \%)$ & $55(100 \%)$ & \\
\hline \multicolumn{8}{|l|}{ Marital status } \\
\hline Married & $17(7.9 \%)$ & $76(35.3 \%)$ & $91(42.3 \%)$ & $21(9.8 \%)$ & $10(4.7 \%)$ & $215(100 \%)$ & \multirow{2}{*}{0.455} \\
\hline Single & $14(9.1 \%)$ & $46(29.9 \%)$ & $68(44.2 \%)$ & $17(11.0 \%)$ & $9(5.8 \%)$ & $154(100 \%)$ & \\
\hline \multicolumn{8}{|l|}{ Family physician } \\
\hline Yes & $5(7.4 \%)$ & $20(29.4 \%)$ & $27(39.7 \%)$ & $10(14.7 \%)$ & $6(8.8 \%)$ & $68(100 \%)$ & \multirow{2}{*}{0.135} \\
\hline No & $26(8.6 \%)$ & $102(33.9 \%)$ & $132(43.9 \%)$ & $28(9.3 \%)$ & $13(4.3 \%)$ & $301(100 \%)$ & \\
\hline \multicolumn{8}{|l|}{ Abnormal findings } \\
\hline Yes & $18(9.9 \%)$ & $63(34.6 \%)$ & $73(40.1 \%)$ & $19(10.4 \%)$ & $9(4.9 \%)$ & $182(100 \%)$ & \multirow{2}{*}{0.295} \\
\hline No & $13(7.0 \%)$ & $59(31.6 \%)$ & $86(46.0 \%)$ & $19(10.2 \%)$ & $10(5.3 \%)$ & $187(100 \%)$ & \\
\hline \multicolumn{8}{|l|}{ Occupation } \\
\hline Blue-collar workers & $24(9.8 \%)$ & $81(33.1 \%)$ & $111(45.3 \%)$ & $21(8.6 \%)$ & $8(3.3 \%)$ & $245(100 \%)$ & \multirow{2}{*}{0.055} \\
\hline White-collar workers & $7(5.6 \%)$ & $41(33.1 \%)$ & $48(38.7 \%)$ & $17(13.7 \%)$ & $11(8.9 \%)$ & $124(100 \%)$ & \\
\hline \multicolumn{8}{|l|}{ Health condition } \\
\hline Good & $5(15.6 \%)$ & $10(31.3 \%)$ & $12(37.5 \%)$ & $2(6.3 \%)$ & $3(9.4 \%)$ & $32(100 \%)$ & \multirow{5}{*}{$0.037^{*}$} \\
\hline Somewhat good & $16(10.3 \%)$ & $60(38.5 \%)$ & $62(39.7 \%)$ & $14(9.0 \%)$ & $4(2.6 \%)$ & $156(100 \%)$ & \\
\hline Average & $3(2.8 \%)$ & $34(31.2 \%)$ & $58(53.2 \%)$ & $11(10.1 \%)$ & $3(2.8 \%)$ & $109(100 \%)$ & \\
\hline Somewhat poor & $5(7.8 \%)$ & $16(25.0 \%)$ & $26(40.6 \%)$ & $9(14.1 \%)$ & $8(12.5 \%)$ & $64(100 \%)$ & \\
\hline Poor & $2(25.0 \%)$ & $2(25.0 \%)$ & $1(12.5 \%)$ & $2(25.0 \%)$ & $1(12.5 \%)$ & $8(100 \%)$ & \\
\hline Total & $31(8.4 \%)$ & $122(33.1 \%)$ & $159(43.1 \%)$ & $38(10.3 \%)$ & $19(5.1 \%)$ & $369(100 \%)$ & \\
\hline
\end{tabular}

Table 3 The association between workers' perceived helpfulness of health consultations by occupational physicians and others factors (i.e., occupational physician's dedication, overtime hours, fatigue accumulation, and privacy protection).

\begin{tabular}{|c|c|c|c|c|c|c|c|}
\hline & $\begin{array}{c}\text { Definitely } \\
\text { agree }\end{array}$ & $\begin{array}{c}\text { Somewhat } \\
\text { agree }\end{array}$ & $\begin{array}{c}\text { Neither agree } \\
\text { nor disagree }\end{array}$ & $\begin{array}{c}\text { Somewhat } \\
\text { disagree }\end{array}$ & $\begin{array}{c}\text { Definitely } \\
\text { disagree }\end{array}$ & Total & $P$ value \\
\hline \multicolumn{8}{|c|}{ Occupational physicians' dedication } \\
\hline Definitely agree & $16(57.1 \%)$ & $6(21.4 \%)$ & $5(17.9 \%)$ & $1(3.6 \%)$ & $0(0.0 \%)$ & $28(100 \%)$ & \multirow{5}{*}{$<0.001 * *$} \\
\hline Somewhat agree & $8(6.9 \%)$ & $72(62.1 \%)$ & $33(28.4 \%)$ & $2(1.7 \%)$ & $1(0.9 \%)$ & $116(100 \%)$ & \\
\hline Neither agree nor disagree & $7(4.1 \%)$ & $41(24.0 \%)$ & $104(60.8 \%)$ & $16(9.4 \%)$ & $3(1.8 \%)$ & $171(100 \%)$ & \\
\hline Somewhat disagree & $0(0.0 \%)$ & $2(4.9 \%)$ & $14(34.1 \%)$ & $17(41.5 \%)$ & $8(19.5 \%)$ & $41(100 \%)$ & \\
\hline Definitely disagree & $0(0.0 \%)$ & $1(7.7 \%)$ & $3(23.1 \%)$ & $2(15.4 \%)$ & $7(53.8 \%)$ & $13(100 \%)$ & \\
\hline \multicolumn{8}{|l|}{ Overtime hours } \\
\hline Definitely agree & $11(11.8 \%)$ & $31(33.3 \%)$ & $32(34.4 \%)$ & $12(12.9 \%)$ & $7(7.5 \%)$ & $93(100 \%)$ & \multirow{5}{*}{0.871} \\
\hline Somewhat agree & $9(7.0 \%)$ & $42(32.8 \%)$ & $59(46.1 \%)$ & $14(10.9 \%)$ & $4(3.1 \%)$ & $128(100 \%)$ & \\
\hline Neither agree nor disagree & $9(7.4 \%)$ & $37(30.6 \%)$ & $58(47.9 \%)$ & $10(8.3 \%)$ & $7(5.8 \%)$ & $121(100 \%)$ & \\
\hline Somewhat disagree & $1(6.7 \%)$ & $6(40.0 \%)$ & $7(46.7 \%)$ & $1(6.7 \%)$ & $0(0.0 \%)$ & $15(100 \%)$ & \\
\hline Definitely disagree & $1(8.3 \%)$ & $6(50.0 \%)$ & $3(25.0 \%)$ & $1(8.3 \%)$ & $1(8.3 \%)$ & $12(100 \%)$ & \\
\hline \multicolumn{8}{|l|}{ Fatigue accumulation } \\
\hline Definitely agree & $13(11.0 \%)$ & $37(31.4 \%)$ & $37(31.4 \%)$ & $19(16.1 \%)$ & $12(10.2 \%)$ & $118(100 \%)$ & \multirow{5}{*}{0.416} \\
\hline Somewhat agree & $6(4.0 \%)$ & $53(35.1 \%)$ & $73(48.3 \%)$ & $15(9.9 \%)$ & $4(2.6 \%)$ & $151(100 \%)$ & \\
\hline Neither agree nor disagree & $9(11.4 \%)$ & $27(34.2 \%)$ & $39(49.4 \%)$ & $2(2.5 \%)$ & $2(2.5 \%)$ & $79(100 \%)$ & \\
\hline Somewhat disagree & $1(7.7 \%)$ & $4(30.8 \%)$ & $7(53.8 \%)$ & $0(0.0 \%)$ & $1(7.7 \%)$ & $13(100 \%)$ & \\
\hline Definitely disagree & $2(25.0 \%)$ & $1(12.5 \%)$ & $3(37.5 \%)$ & $2(25.0 \%)$ & $0(0.0 \%)$ & $8(100 \%)$ & \\
\hline \multicolumn{8}{|l|}{ Privacy protection } \\
\hline Definitely agree & $17(36.2 \%)$ & $12(25.5 \%)$ & $13(27.7 \%)$ & $3(6.4 \%)$ & $2(4.3 \%)$ & $47(100 \%)$ & \multirow{5}{*}{$<0.001 * *$} \\
\hline Somewhat agree & $7(6.4 \%)$ & $68(61.8 \%)$ & $28(25.5 \%)$ & $6(5.5 \%)$ & $1(0.9 \%)$ & $110(100 \%)$ & \\
\hline Neither agree nor disagree & $6(3.4 \%)$ & $39(21.8 \%)$ & $104(58.1 \%)$ & $20(11.2 \%)$ & $10(5.6 \%)$ & $179(100 \%)$ & \\
\hline Somewhat disagree & $0(0.0 \%)$ & $2(8.3 \%)$ & $12(50.0 \%)$ & $6(25.0 \%)$ & $4(16.7 \%)$ & $24(100 \%)$ & \\
\hline Definitely disagree & $1(11.1 \%)$ & $1(11.1 \%)$ & $2(22.2 \%)$ & $3(33.3 \%)$ & $2(22.2 \%)$ & $9(100 \%)$ & \\
\hline Total & $31(8.4 \%)$ & $122(33.1 \%)$ & $159(43.1 \%)$ & $38(10.3 \%)$ & $19(5.1 \%)$ & $369(100 \%)$ & \\
\hline
\end{tabular}

Note: Kruskal-Wallis test was performed for occupational physicians' dedication, overtime hours, fatigue accumulation, and privacy protection.

**: $P<0.01$ 
Table 4 Factors associated with workers' perceived helpfulness of health consultations by occupational physicians.

\begin{tabular}{lcrc}
\hline & $\begin{array}{c}\text { Standard partial } \\
\text { regression coefficient }\end{array}$ & $P$ value & VIF \\
\hline Age & -0.011 & 0.817 & 1.518 \\
Marital status & 0.066 & 0.138 & 1.265 \\
Family physician & $-0.101^{*}$ & 0.015 & 1.084 \\
Abnormal findings & 0.037 & 0.412 & 1.282 \\
Occupation & $0.121^{* *}$ & 0.004 & 1.105 \\
Health condition & -0.029 & 0.493 & 1.170 \\
Occupational physicians & $0.532^{* *}$ & $<0.001$ & 1.209 \\
$\quad$ dedication & -0.032 & 0.484 & 1.332 \\
Overtime hours & 0.004 & 0.927 & 1.368 \\
Fatigue accumulation & $0.226^{* *}$ & $<0.001$ & 1.199 \\
Privacy protection & 0.423 & & \\
\hline Adjusted R square &
\end{tabular}

Note: Coding of dichotomous variables were as follows: marital status (Married $=1$, Single $=0$ ); family physician (Yes $=1$, $\mathrm{No}=0$ ); abnormal findings (Yes $=1, \mathrm{No}=0$ ); occupation (Bluecollar worker $=1$, White-collar worker $=0$ ).

The subjects' actual ages were used.

Concerning the health condition, 1 to 5 points were given in the order from "poor" to "good."

Concerning the occupational physicians' dedication, overtime hours, fatigue accumulation, and privacy protection, 1 to 5 points were given in the order from "definitely disagree" to "definitely agree."

Concerning the workers' perceived helpfulness of health consultations by occupational physicians, 1 to 5 points were given in the order from "definitely disagree" to "definitely agree."

*: $P<0.05 \quad * *: P<0.01$

working-hour group was significantly higher than that of those in the short-working-hour group.

Sokejima et al. ${ }^{[3]}$ reported that the odds ratio of cardiac infarction of the group of workers whose average daily working time was 11 hours was 2.44 , and that of the group of workers whose average daily working time was less than 7 hours was 3.07, compared with the group of workers whose average daily working time was 7-9 hours. The reason shorttime workers have high morbidity ratios is that they may have suffered some diseases and, therefore, have shortened their working time to help them maintain a better standard of health.

Long working hours makes it difficult to get a sufficient amount of sleep and causes fatigue accumulation. Although the previous study reported that a lack of sleep impairs health, ${ }^{[11]-[13]}$ overwork increases the risk of serious health impairment to workers, such as hypertension and cardiac infarction. ${ }^{[1]-[3]}$ Therefore, it is an important issue for discussion in the field of occupational health activities. To help reduce the risk of workers' health impairment, health consultations by occupational physicians have proven extremely effective.

Among employees who felt that privacy protection was observed, there were many who thought that health consultations by occupational physicians were helpful. If workers are anxious about the leakage of their private information and therefore refrain from conveying their health conditions to occupational physicians, it may hamper the early detection of a disease. Thus, it is evident that it is mandatory to implement thorough measures for privacy protection.

Among workers who felt that occupational physicians were dedicated, there were many who thought that health consultations by occupational physicians were helpful. If employees trust occupational physicians, it would be expected that they would want to undergo health consultations given by occupational physicians. According to the reports on the survey of patients' satisfaction, when their satisfaction concerning physicians is high, their compliance increases. ${ }^{[6]-[8]} \mathrm{We}$ suppose this would also be true concerning health consultations given by occupational physicians. If workers do not trust occupational physicians, they become reluctant to receive their health consultations. And therefore, occupational physicians become unable to properly determine employees' health conditions and working environments. In such situations, occupational physicians cannot provide appropriate health consultations.

The amended Industrial Safety and Health Law ${ }^{[4]}$ especially emphasizes two main points for workers, "overtime hours" and "fatigue accumulation." However, for occupational physicians' health consultations to be effective, it is necessary to not only discuss "overtime hours" and "fatigue accumulation" but also to help employees realize the physicians' outstanding dedication and to convey to the workers the absolute assurance of their privacy protection.

Employees who have a family physician were generally of the opinion that health consultations by occupational physicians are not helpful compared with those who do not have a family physician. It is most likely that employees who have a family physician do not feel the necessity for health consultations by occupational physicians because of the very fact they already have a reliable and trusted physician in whom they can consult.

White-collar workers are also of the general opinion that health consultations by occupational physicians are not helpful compared with blue-collar workers. The number of employees with a high level of education is naturally higher among white-collar compared with blue-collar workers. Therefore, because white-collar workers may have a better knowledge of their own health maintenance, they may not feel a necessity for health consultations given by occupational physicians.

Such consultations could provide an opportunity to obtain essential information for such actions as, personnel relocation, reducing the number of hours employees work overtime, and providing adequate occupational heath education for employees. Of course, it is important for workers to have a good knowledge of heath maintenance and, whenever possible, to have a family physician. However, it is also necessary to convey the importance of health consultations for employees given by occupational physicians.

The subjects of this survey were 369 workers engaged in the departments of development design and manufacturing of industrial products, limiting the study subjects. This is the limitation of this study. The second limitation lies in the fact that although 402 of 497 questionnaires were collected 
(80.9\% response rate), and because questionnaires with missing values and those of the 12 female workers were excluded, only 369 questionnaires were analyzed. Thus, the opinions of 128 subjects were not included in this study. The third limitation was that we used a cross-sectional design, which made it difficult to evidence any identifying factors referring to causal relationships as compared with those that would be afforded from a cohort study. In future studies, it will be necessary to collect data of factors associated with workers' perceived helpfulness of health consultations given by occupational physicians.

\section{ACKNOWLEDGEMENTS}

The survey in this study was carried out with the support of the employees of a manufacturing plant. We would like to thank those who helped conduct this study.

\section{REFERENCES}

[1] Hayashi T, Kobayashi Y, Yamaoka K, Yano E: Effect of overtime work on 24-hour ambulatory blood pressure. J Occup Environ Med 38: 1007-1011, 1996

[2] Iwasaki K, Sasaki T, Oka T, Hisanaga N: Effect of working hours on biological functions related to cardiovascular system among salesmen in a machinery manufacturing company. Ind Health 36: 361-367, 1998

[3] Sokejima S, Kagamimori S: Working hours as a risk factor for acute myocardial infarction in Japan: case-control study. BMJ 317: 775-780, 1998

[4] Japan Industrial Safety and Health Association (compiler): Outline of the Occupational Health and Safety Law that was Amended in 2005, Tokyo: Japan Industrial Safety and Health Association, 2006 (in Japanese)

[5] CHI (Consulting team for Healthy Company) (compiler): Innovations for the Healthy Company-for the people who are engaged in the health of the 21st century companies-, Kanagawa: Bio Communications INC, 2001 (in Japanese)

[6] Rosenberg MJ, Waugh MS, Burnhill MS. Compliance: counseling and satisfaction with oral contraceptives: a prospective evaluation. Fam Plann Perspect 30: 89-92, 104, 1998

[7] Roberts KJ: Physician-patient relationships, patient satisfaction, and antiretroviral medication adherence among HIVinfected adults attending a public health clinic. AIDS Patient Care STDS 16: 43-50, 2002

[8] Sinha PK, Nanda RS, McNeil DW: Perceived orthodontist behaviors that predict patient satisfaction, orthodontistpatient relationship, and patient adherence in orthodontic treatment. Am J Orthod Dentofacial Orthop 110: 370-377, 1996

[9] Health, Labor and Welfare Ministry: The Heisei 11 Study of Searching for Diagnostic Activities, Tokyo: Kousei Toukei Kyoukai, 2001 (in Japanese)

[10] Uchida O: Chapter 3: Multiple regression analysis. In: Multivariate analysis of questionnaire using SPSS. Tokyo: Tokyotosho, 2003, 31-51 (in Japanese)

[11] Wingard DL, Berkman LF: Mortality risk associated with sleeping patterns among adults. Sleep 6: 102-107, 1983

[12] Belloc NB, Breslow L: Relationship of physical health status and health practices. Prev Med 1: 409-421, 1972

[13] Kurasawa T, Yamauchi S, Sekizawa T, Nakatsuka H: Sleeping hours and cardiovascular in treated hypertensive patients. Naika 71: 349-352, 1993 (in Japanese)

\section{APPENDIX The Questionnaire (The original ver- sion is in Japanese.)}

\section{Question set 1: Fill in your age and check or circle the appropriate boxes and numbers.}

1. Age:

2. Gender: years old)

3. Marital status:

$\begin{array}{ll}\square \text { Male } & \square \text { Female } \\ \square \text { Married } & \square \text { Single }\end{array}$

4. Have you ever received a result card with any abnormal findings after a health checkup?

$\square$ Yes

No

5. Do you have a family physician (you can consult with about health issues without reserve) (excluding physicians who manage the workers' health at your company (e.g., occupational physicians))? $\square$ Yes $\square$ No

6. Which is your routine work: Blue-collar work engaged mainly in on-site tasks or white-collar work mainly doing deskwork? $\square$ Blue-collar $\square$ White-collar

7. How is your general health condition?
5. Good
4. Somewhat good
3. Average
2. Somewhat poor
1. Poor

Question set 2: Circle your answer regarding your everyday thoughts.

1. Do you think that physicians who manage the workers' health at your company (e.g., occupational physicians) make every possible effort to perform health maintenance for all of the employees?
5. Definitely agree
4. Somewhat agree
3. Neither agree nor disagree
2. Somewhat disagree 1. Definitely disagree

2. Do you feel there is a lot of overtime in your company? (Overtime is defined as work after a routine 8-hour workday, and any work on Saturdays, Sundays, and/or holidays.)
5. Definitely agree
4. Somewhat agree
3. Neither agree nor disagree
2. Somewhat disagree
1. Definitely disagree

3. Do you often feel the accumulation of physical and/or mental fatigue due to the workload at your company?
5. Definitely agree
4. Somewhat agree
3. Neither agree nor disagree
2. Somewhat disagree
1. Definitely disagree

4. Do you think that your company observes privacy protection regarding the information concerning employees' health?
5. Definitely agree
4. Somewhat agree
3. Neither agree nor disagree
2. Somewhat disagree 1 . Definitely disagree

5. Do you think that consultations with physicians who manage workers' health at your company (e.g., occupational physicians) are helpful for you to keep working in good mental and physical health?
5. Definitely agree
4. Somewhat agree
3. Neither agree nor disagree
2. Somewhat disagree 1. Definitely disagree 